J.G. Ramsay MD, B.D. Higgs MB BS, J.E. Wynands MD, R. Robbins MD, G.E. Townsend MD

\title{
Early extubation after high-dose fentanyl anaesthesia for aortocoronary bypass surgery: reversal of respiratory depression with low-dose nalbuphine
}

To investigate the possibility of selective reversal of narcotic-induced respiratory depression following fentanyl anaesthesia, we studied 20 patients after aortocoronary bypass surgery. All patients were anaesthetized with fentanyl. $40 \mu \mathrm{g} \cdot \mathrm{kg}^{-1}$ and oxygen, with isofturane as indicated. In a random double blind fashion either incremental doses of nalbuphine, or normal saline were administered approximately four hours after cardiopulmonary bypass. Respiratory depression was evaluated using blood gas and end tidal $\mathrm{CO}_{2}\left(\mathrm{PETCO}_{2}\right)$ measurement, and in addition, a ventilatory response to $\mathrm{CO}_{2}$ was obtained preoperatively and at selected intervals postoperatively. Despite randomization, patients with more respiratory depression were assigned to nalbuphine. There appeared to be a reversal of respiratory depression with nalbuphine, indicated by a fall in the resting $\mathrm{PETCO}_{2}$ value. This

Key words

ANAESTHETICS, INTRAVENOUS: fentanyl; ANTAGONISTS, NARCOTICS: nalbuphine; ENDOTRACHEAL. TUBE: extubation.

From the Department of Anaesthesia, Royal Victoria Hospital and McGill University, Montreal, Quebec. No reprints will be available.

Address correspondence to: Dr. J.G. Ramsay, Department of Anaesthesia, Royal Victoria Hospital, 687 Pine Avenue West, Montreal, Quebec, H3A 1A1.

Supported by a grant from the Canadian Heart Foundation. apparent reversal of respiratory depression was associated with a significant increase in pain, requiring treatment in three patients. We conclude that low-dose nalbuphine is not an acceptable method of antagonism of respiratory depression in this group of patients. Many patients who did not receive nalbuphine were able to breathe adequately at an earlier stage than was previously suspected. Close monitoring of the respiratory system may permit earlier extubation without the requirement of a narcotic antagonist after this dose of fentanyl.

High-dose fentanyl anaesthesia has become a technique of choice for cardiac surgery due to haemodynamic stability and absence of adverse effects. ${ }^{1,2}$ Conventional management of patients after this type of surgery usually includes a period of elective ventilation in the intensive care unit for 6 to 24 hours, regardless of the type of anaesthesia. After high doses of fentanyl, this period allows the narcotic-induced respiratory depression to wear off. In the absence of large doses of narcotic, however, recent studies show that extubation within six hours of cardiac surgery is not associated with complications, and may in fact reduce morbidity. ${ }^{3-5}$ After abdominal aortic reconstructive surgery, early extubation may permit earlier normalization of the FRC. ${ }^{6}$ Other advantages include reduced intensive care unit and hospital stay, ${ }^{4}$ and reduced requirements for sedation. ${ }^{3}$

Nalbuphine is one of the newer "agonist- 
antagonist" opiates, thought to have a greater affinity for those opiate receptors mediating analgesia than those causing respiratory depression. ${ }^{7}$ It has been used in high doses prior to cardiac surgery with good haemodynamic stability, ${ }^{8}$ and has been used to reverse postoperative respiratory depression due to oxymorphine and dihydromorphine. ${ }^{9}$ In the latter case, analgesia was preserved, and blood pressure and pulse rose only to pre-anaesthetic levels. Nalbuphine has recently been reported to reverse postoperative respiratory depression due to fentanyl, without reversal of analgesia. ${ }^{10}$

Preliminary observations suggested to us that small doses of nalbuphine (less than $10 \mathrm{mg}$ ) could reverse the postoperative respiratory depression resulting from a dose of $40 \mathrm{mg} \cdot \mathrm{kg}^{-1}$ of fentanyl for aortocoronary bypass surgery, while allowing patients to remain analgesic and haemodynamically stable. Based on a plasma level of fentanyl of approximately $14 \mathrm{ng} \cdot \mathrm{ml}^{-1}$ at the beginning of the elimination phase, " and an elimination half-life of approximately four hours, ${ }^{12}$ pharmacodynamics of fentanyl are such that in a $70 \mathrm{~kg}$ man, plasma levels at which significant respiratory depression occurs (elevation of end-tidal $\mathrm{CO}_{2}$ by $1.3 \mathrm{kPa}(10 \mathrm{mmHg})$ ) may be expected for approximately 12 hours after this dose. ${ }^{12}$ If nalbuphine, with a half life of 3.5 hours after coronary artery surgery ${ }^{13}$ is given approximately eight hours after administration of fentanyl, then plasma levels of fentanyl below those causing significant respiratory depression should be reached by one half-life of nalbuphine. Thus, nalbuphine could be administered at this time with little fear of "renarcotization."

We wished to assess the efficacy of nalbuphine in selective reversal of postoperative respiratory depression, after a dose of $40 \mu \mathrm{g} \cdot \mathrm{kg}^{-1}$ of fentanyl for aortocoronary bypass surgery. We wished also to compare the postoperative course of patients treated with nalbuphine and extubated early to a similar group of patients who did not receive nalbuphine. Our goal was to provide patients with the demonstrated advantages of both high-dose fentanyl anaesthesia and early extubation.

\section{Methods}

Twenty patients undergoing elective aortocoronary bypass surgery were studied. Informed consent was obtained from all patients the day prior to surgery, and the study was approved by the hospital ethics committee. The criteria for entry of a patient into the study were: left ventricular ejection fraction greater than 0.5 ; no history of pulmonary disease; normal preoperative chest $x$-ray and blood gases; and no major extracardiac systemic disease.

The day prior to surgery patients were given a $\mathrm{CO}_{2}$ challenge, using a modified Read technique. ${ }^{14}$ During this procedure (taking three to four minutes) a modified lead II EKG was monitored continuously while the patient rebreathed a mixture of five per cent $\mathrm{CO}_{2}$ in 95 per cent $\mathrm{O}_{2}$ through a pneumotachograph and $\mathrm{CO}_{2}$ analyser (Hewlett Packard, Model 47210-A). This enabled determination of the slope of the ventilatory response to $\mathrm{CO}_{2}$ where minute ventilation is plotted vs end tidal $\mathrm{CO}_{2}$ concentration $\left(\mathrm{PETCO}_{2}\right)$.

Patients were maintained on their preoperative medications until the night before surgery, with the exception of beta-blockers, nitrate preparations and calcium channel antagonists, which were continued up to the time of the operation. The patients were premedicated with diazepam $\left(0.15 \mathrm{mg} \cdot \mathrm{kg}^{-1}\right.$ given orally), morphine $\left(0.15 \mathrm{mg} \cdot \mathrm{kg}^{-1} \mathrm{IM}\right)$ and scopolamine $\left(0.005 \mathrm{mg} \cdot \mathrm{kg}^{-1} \mathrm{IM}\right)$ one hour before induction of anaesthesia. Oxygen was administered by nasal prongs while intravenous, intra-arterial, and pulmonary artery catheters were inserted under local anaesthesia in the operating theatre.

Anaesthesia was induced with fentanyl (40 $\mu \mathrm{g} \cdot \mathrm{kg}^{-1}$ ) given at a rate of $1 \mathrm{mg} \cdot \mathrm{min}^{-1}$. Fentanyl was preceded by $1 \mathrm{mg}$ of pancuronium to prevent chest wall rigidity, with additional pancuronium given to a total dose of $0.1 \mathrm{mg} \cdot \mathrm{kg}^{-1}$, after loss of consciousness. Patients were ventilated with 100 per cent $\mathrm{O}_{2}$ using a modified $\mathrm{T}$-piece and fresh gas flows to maintain normocarbia. Anaesthesia was supplemented with isoflurane as required, but no additional opiates or sedatives were given. Fluid management, vasoactive drugs and inotropes were titrated to haemodynamic measurements.

Patients were transferred to the postoperative intensive care unit with the endotracheal tube in situ, and controlled intermittent positive pressure ventilation with a Bennett MA 1 ventilator was instituted. All patients fulfilled the following criteria before continuing in the study: (1) rectal temperature greater than $37.5^{\circ} \mathrm{C}$; (2) minimal bleeding; (3) blood pressure and pulmonary capillary wedge pressure close to preoperative values; (4) heart rate less than $100 \mathrm{~min}$; (5) responsive to commands; (6) normal neuromuscular function (sustained grasp); (7) pain free; (8) no gross pathology apparent on 
TABLE I Study protocol

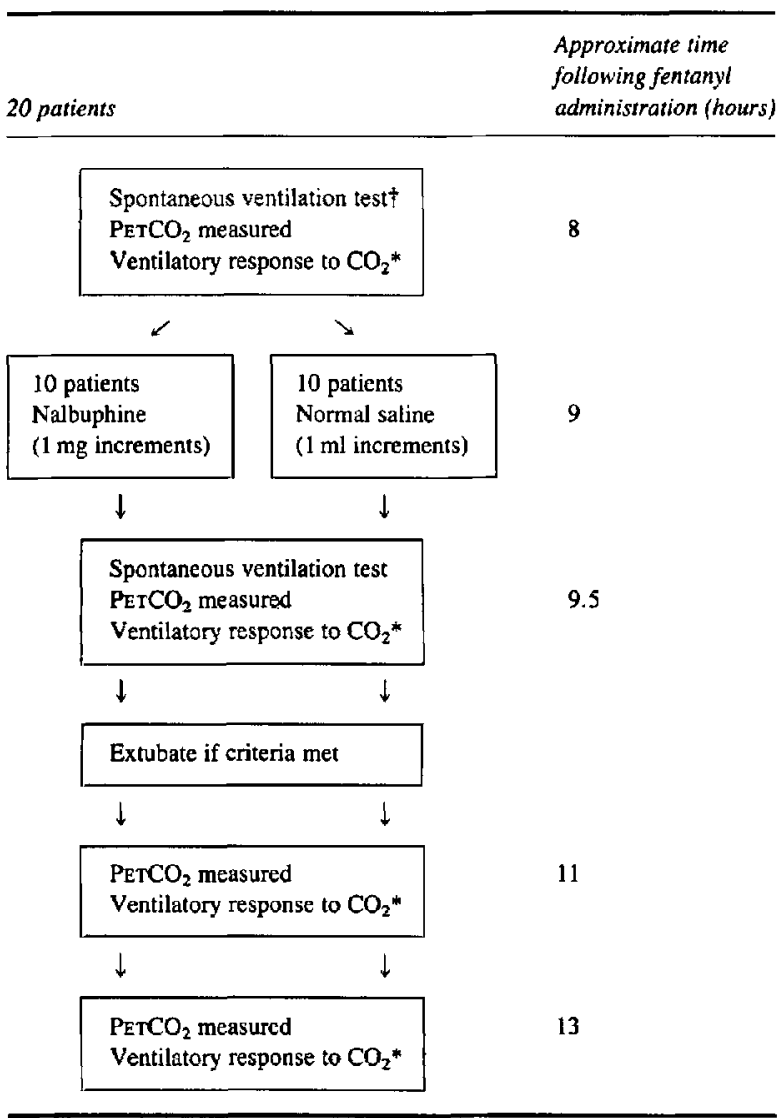

†IMV set at 4 breaths per minute.

-Only in patients with $\mathrm{PETCO}_{2}$ less than $8 \mathrm{kPa}$

chest $x$-ray; (9) acceptable arterial blood gases (pH 7.35-7.45, $\mathrm{PaCO}_{2} 4.7-6.0 \mathrm{kPa}(35-45 \mathrm{mmHg})$, $\mathrm{PaO}_{2}$ greater than $13.3 \mathrm{kPa}(100 \mathrm{mmHg})$ on $\mathrm{FIO}_{2}$ of less than $0.5, \mathrm{HCO}_{3}^{-} 23-27 \mathrm{mEq} \cdot \mathrm{L}^{-1}$ ).

$\mathrm{PETCO}_{2}$ was measured continuously, and blood gas measurements were taken regularly to confirm the accuracy of the PETCO 2 measurements. During all spontaneous ventilation tests (vide infra), measurement of ventilatory responses to $\mathrm{CO}_{2}$, and during administration of test drugs EKG, blood pressure and pulmonary artery pressure were continuously observed by one of the investigators or the patient's nurse.

When the above criteria were fulfilled, the patient was allowed to breathe spontaneously on an intermittent mandatory ventilation circuit (IMV) set at a rate of 4 breaths $\cdot \min ^{-1}$ for five minutes. $\mathrm{A} \mathrm{CO}_{2}$ response curve was obtained only in patients who breathed to an $\mathrm{PETCO}_{2}$ of less than $8.0 \mathrm{kPa}$. Controlled ventilation was then reinstituted until PeTCO ${ }_{2}$ returned to $4.7-6.0 \mathrm{kPa}$. The IMV circuit was once again connected, set at 4 breaths $\cdot \mathrm{min}^{-1}$, and patients were given either normal saline (ten patients) or nalbuphine (ten patients) in a randomized double-blind manner. Ten $\mathrm{ml}$ syringes contained either normal saline $10 \mathrm{ml}$, or nalbuphine $10 \mathrm{mg}$ made up to $10 \mathrm{ml}$ with sterile saline (concentration of $1 \mathrm{mg} \cdot \mathrm{ml}^{-1}$ ). The syringe contents were given at a maximum rate of $1 \mathrm{ml}$ every three minutes, until the patient experienced either discomfort or pain, or until all $10 \mathrm{ml}$ were given. The experimental protocol is illustrated in Table I.

The IMV breaths were discontinued as soon as a $\mathrm{PETCO}_{2}$ of less than $6.7 \mathrm{kPa}(50 \mathrm{mmHg})$ was 
TABLE II Anthropomorphic data, drug history, and recovery times (mean \pm SEM)

\begin{tabular}{|c|c|c|c|c|c|c|c|c|c|}
\hline & \multirow{2}{*}{$\begin{array}{l}\text { Age } \\
\text { (years) }\end{array}$} & \multirow{2}{*}{$\begin{array}{l}\text { Height } \\
\text { (cms) }\end{array}$} & \multirow{2}{*}{$\begin{array}{l}\text { Weight } \\
(k g)\end{array}$} & \multicolumn{4}{|c|}{$\begin{array}{l}\text { Drugs taken } \\
\text { (no. patients) }\end{array}$} & \multirow{2}{*}{$\begin{array}{l}\text { Time in } O R \\
\text { (hrs) }\end{array}$} & \multirow{2}{*}{$\begin{array}{l}\text { Time to } 37.5^{\circ} \mathrm{C} \\
\text { Post fentanyl } \\
\text { (hrs) }\end{array}$} \\
\hline & & & & $B B$ & $C a A$ & $N$ & 0 & & \\
\hline $\begin{array}{l}\text { Saline group } \\
\qquad(\mathrm{n}=10)\end{array}$ & $57 \pm 1.6$ & $172 \pm 1.8$ & $75 \pm 1.7$ & 10 & 8 & 5 & 3 & $4.2 \pm 0.3$ & $8.4 \pm 0.3$ \\
\hline $\begin{array}{l}\text { Nalbuphine group } \\
\quad(n=10)\end{array}$ & $53 \pm 2.7$ & $172 \pm 2.2$ & $78 \pm 3.3$ & 8 & 7 & 5 & 4 & $3.8 \pm 0.3$ & $7.9 \pm 0.2$ \\
\hline
\end{tabular}

Key: $\mathrm{BB}=$ Beta Blockers; $\mathrm{CaA}=$ calcium antagonist; $\mathbf{N}=$ nitrates; $\mathrm{O}=$ other drugs (diuretics, ASA, quinidine).

maintained spontaneously. Immediately following drug administration the resting $\mathrm{PETCO}_{2}$, and a $\mathrm{CO}_{2}$ response curve (in patients breathing to a $\mathrm{PETCO}_{2}$ of less than $8.0 \mathrm{kPa}$ ) were obtained. Patients were extubated if they were awake and co-operative and had acceptable arterial blood gases ( $\mathrm{pH}$ greater than 7.3, $\mathrm{PaCO}_{2}$ less than $6.7 \mathrm{kPa}, \mathrm{PaO}_{2}$ greater than $13.3 \mathrm{kPa}$ on an $\mathrm{FlO}_{2}$ of less than $0.5, \mathrm{HCO}_{3}^{-}$ greater than $22 \mathrm{mEq} \cdot \mathrm{L}^{-1}$ ). Further measurements of resting $\mathrm{PETCO}_{2}$ and $\mathrm{PaCO}_{2}$, and $\mathrm{CO}_{2}$ response curves were made at one and three hours postextubation. Controlled ventilation was continued in those patients who did not meet the requirements for extubation after drug administration. They were extubated when they fulfilled these requirements, but further $\mathrm{CO}_{2}$ response curves were not obtained in these patients.

Initially, a linear analogue scale for pain (15) was explained at the preoperative visit and used in the postoperative intensive care unit. It became clear, however, that patients experienced difficulty in using a visual scale at this time. For this reason, pain was assessed by direct questioning, beginning with "Are you comfortable?" If patients experienced incisional pain that was increasing during the administration of the test drug, then administration was terminated. If the pain continued to increase or was intolerable (as judged by restlessness, visible discomfort, or response to direct questioning) then morphine was administered. Patients were questioned prior to each injection (of $1 \mathrm{ml}$ solution) or more frequently if indicated. The following scale was used to record pain:

$$
\begin{aligned}
& 0 \text { - comfortable } \\
& \pm- \text { slight discomfort } \\
& +- \text { tolerable pain, not increasing } \\
+ & +- \text { increasing pain (drug administration was } \\
& \text { terminated) } \\
++ & \text { - pain requiring morphine. }
\end{aligned}
$$

Tachycardia (heart rate greater than 100 min) was treated with increments of propranolol, and hypertension (systolic pressure greater than $2.7 \mathrm{kPa}$ ( $20 \mathrm{mmHg}$ ) above preoperative value) was treated with either nitroglycerine or nitroprusside infusion. Nausea was treated with droperidol $1.25 \mathrm{mg}$, in the absence of abdominal distension.

Morphine requirements in the 12 hours following drug administration were recorded. Chest $x$-ray and EKG were assessed immediately postoperatively, and at 24 and 48 hours. Blood loss and blood/fluid requirements were assessed over the 24 -hour postoperative period.

Statistical analysis was made using two-way analysis of variance with Duncan's multiple range test for identification of differences within the analysis of variance. Friedman's test statistic and chi-square analysis were also used where appropriate. The null hypothesis was rejected when $p$ was less than 0.05 . Linear regression was used 10 calculate the slope of the $\mathrm{CO}_{2}$ response curves. All values are quoted as mean \pm 1 standard error of the mean.

\section{Results}

The anthropomorphic details of the subjects studied, a list of their medications, and the operative and recovery times are given in Table II. The two groups are comparable in all respects.

\section{Antagonism of respiratory depression}

\section{RESTING PetCO $\mathrm{P}_{2}$ Results}

Table III gives the resting PETCO$_{2}$ results at the various times. In the saline group the only differences in resting $\mathrm{PETCO}_{2}$ appear between the preoperative and the pre-saline, and the preoperative and post-saline values. There was no significant effect of administration of saline on resting $\mathrm{PETCO}_{2}$, and 
TABLE III Respiratory parameters

\begin{tabular}{|c|c|c|c|c|c|}
\hline & \multicolumn{5}{|l|}{ Saline group } \\
\hline & Preoperative & Pre-saline & Post-saline & Post-extubation & 3 hours Post-extubation \\
\hline \multirow{8}{*}{$\begin{array}{l}\text { Time post-fentanyl } \\
\text { (hrs) } n=10 \\
\text { Resting PETCO } \\
\text { (kPa) } \mathrm{n}=10 \\
\text { Slope of response to } \mathrm{CO}_{2} \\
\left(\mathrm{~L} \cdot \mathrm{min}^{-1} \cdot \mathrm{kPa}^{-1}\right) \mathrm{n}=7 \\
\end{array}$} & & & & & \\
\hline & & $8.4 \pm 0.3$ & $9.4 \pm 0.3$ & $11.1 \pm 0.3$ & $13.1 \pm 0.3$ \\
\hline & $=04+0$ & & & & \\
\hline & $5.24 \pm 0.19$ & $7.17 \pm 0.35^{*}$ & $6.65 \pm 0.25^{*}$ & $6.10 \pm 0.23$ & $6.09 \pm 0.23$ \\
\hline & $4.35+0.97$ & $578+120$ & $795+201$ & $420+105$ & $4.73-0.53$ \\
\hline & (n) & 然 & 年 & 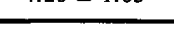 & 17. -0.00 \\
\hline & \multicolumn{5}{|c|}{ Nalbuphine group } \\
\hline & Preoperative & Pre-nalbuphine & Post-ralbuphine & Post-extubation & 3 hours Post-extubation \\
\hline \multicolumn{6}{|l|}{ Time post-fentanyl } \\
\hline \multicolumn{6}{|l|}{ Resting $\mathrm{PETCO}_{2}$} \\
\hline (kPa) $n=7$ & $5.44 \pm 0.12$ & $8.20 \pm 0.47^{*}$ & $6.48 \pm 0.29 * \dagger$ & $6.49 \pm 0.23 * \dagger$ & $6.49 \pm 0.20^{*} \dagger$ \\
\hline \multicolumn{6}{|l|}{ Slope of response to $\mathrm{CO}_{2}$} \\
\hline$\left(\mathrm{L} \cdot \mathrm{min}^{-1} \cdot \mathrm{kPa}^{-1}\right) \mathrm{n}=7$ & $4.58 \pm 0.53$ & & $4.65 \pm 1.50$ & $4.88 \pm 0.83$ & $3.83 \pm 1.20$ \\
\hline
\end{tabular}

*indicates $p<0.05$ vs preoperative; tindicates $p<0.05$ vs pre-nalbuphine.

by the time the post-extubation values were recorded the mean value had fallen sufficiently that it was not different from the preoperative value.

In the nalbuphine group three of the patients required morphine during the administration of nalbuphine (vide infra), and these patients were dropped from the analysis. For the other seven patients, the preoperative PETCO $\mathrm{C}_{2}$ was significantly lower than all subsequent values, and the prenalbuphine value was significantly higher than all post-nalbuphine values. Administration of nalbuphine was associated with a significant lowering of the resting $\mathrm{PETCO}_{2}$; however, it remained above the preoperative value.

Comparing the values between groups (unpaired $t$ test), the resting $\mathrm{PerCO}_{2}$ was higher in the saline group than the nalbuphine group before administration of the test drug ( $p<0.05$ ). Otherwise there was no difference between groups at any time.

SLOPE OF THE VENTILATORY RESPONSE TO $\mathrm{CO}_{2}$ Postoperatively we did not subject patients with resting $\mathrm{PETCO}_{2}$ of greater than $8 \mathrm{kPa}$ to a formal $\mathrm{CO}_{2}$ challenge (Read rebreathing). This meant that seven of the patients in the nalbuphine group and three in the saline group could not have an objective assessment of the slope of their $\mathrm{CO}_{2}$ response before administration of the test drug.

The three patients in the saline group were dropped from the analysis of variance, which when performed on the remaining seven patients indicated no significant difference between the slopes measured at the times indicated (Table III). Although the slope after administration of saline appeared to be increased compared to the preoperative value, there was a large range in results (indicated by the large standard error) and considerable within-patient variability.

Rather than drop all seven patients from the nalbuphine group results, we elected to analyse the slopes of the $\mathrm{CO}_{2}$ response in this group at all times except before administration of the drug. The three patients in this group who required morphine were dropped from the analysis. For the remaining seven patients, analysis of variance revealed no difference between the slopes at the times shown (Table III).

As lack of spontaneous ventilation despite a $\mathrm{PETCO}_{2}$ of greater than $8 \mathrm{kPa}$ might be considered as an "absent" ventilatory response to $\mathrm{CO}_{2}$ (up to this level), Friedman's rank test was performed on the slope of the $\mathrm{CO}_{2}$ response results, assigning the lowest value to patients who did not have a formal $\mathrm{CO}_{2}$ challenge because of their high resting PETCO $\mathrm{C}_{2}$. A comparison was then possible using all ten patients within each group, at the preoperative, pre-drug, and post-drug times. Again, due to the within-patient variability this test failed to reach statistical significance. 
TABLE IV Non-respiratory effects of saline/nalbuphine administration

\begin{tabular}{|c|c|c|c|c|c|c|}
\hline \multirow[b]{2}{*}{ Subject no. } & \multirow{2}{*}{$\begin{array}{l}\text { mi drug } \\
\text { injectedo }\end{array}$} & \multicolumn{2}{|c|}{$P A N N$} & \multirow[b]{2}{*}{ Nausea } & \multirow{2}{*}{$\begin{array}{l}B P \text { or } H R \\
\text { increase }\end{array}$} & \multirow[b]{2}{*}{ Treatment } \\
\hline & & pre & post & & & \\
\hline \multicolumn{7}{|c|}{ (saline group) } \\
\hline 1 & 10 & - & - & - & - & - \\
\hline 2 & 10 & - & - & - & + & Propranolol \\
\hline 3 & 10 & - & - & - & - & - \\
\hline 4 & 10 & - & - & - & - & - \\
\hline 5 & 10 & - & + & - & + & - \\
\hline 6 & 10 & \pm & - & - & - & - \\
\hline 7 & 10 & - & + & - & - & - \\
\hline 8 & 10 & - & - & - & - & - \\
\hline 9 & 10 & - & - & + & - & Droperidol \\
\hline 10 & 10 & - & - & - & - & - \\
\hline \multicolumn{7}{|c|}{ (nalbuphine group) } \\
\hline 11 & 2 & \pm & ++ & - & + & Propranolol, nitro-prusside \\
\hline 12 & 4 & - & ++ & + & + & Droperidol \\
\hline 13 & 4 & - & +++ & - & - & Morphine \\
\hline 14 & 10 & - & - & - & + & Propranolal \\
\hline 15 & 10 & - & + & + & + & Droperidol, propranolol, nitroglycerin \\
\hline 16 & 10 & - & - & - & - & - \\
\hline 17 & 2 & \pm & ++ & - & - & - \\
\hline 18 & 2 & - & +++ & + & + & Morphine \\
\hline 19 & 6 & - & ++ & - & - & - \\
\hline 20 & 5 & - & +++ & - & + & Morphine, althesin \\
\hline \multicolumn{7}{|l|}{$P$ value } \\
\hline (chi square) & & NS & 0.025 & NS & NS & 0.025 \\
\hline
\end{tabular}

a - normal saline, or nalbuphine $1 \mathrm{mg} \cdot \mathrm{kg}^{-1}$.

See text for definitions of pain, nausea, BP or HR increase and treatment.

There was no difference in slopes between groups at any time.

\section{Non-respiratory effects}

Two patients experienced tolerable pain during the saline administration, and one of these also showed a transient increase in heart rate and blood pressure which did not require treatment (Table IV). There were few other effects in this group, and all patients received the entire contents of the test syringe $(10 \mathrm{ml})$.

In contrast, one patient in the nalbuphine group experienced tolerable pain during the drug administration, while four others experienced increasing pain necessitating that the drug administration be stopped. None of these patients required analgesia once the drug administration had been stopped, however. Three patients experienced more severe pain, requiring that intravenous morphine be given. It was necessary to sedate one of these patients with an alfathesin infusion as he remained agitated after $15 \mathrm{mg}$ of intravenous morphine. Thus only three patients in this group did not experience pain as a result of the drug administration, and only these three patients received the full contents of the syringe $(10 \mathrm{ml})$.

Three patients who received nalbuphine required droperidol for nausea, six became hypertensive (two of which required treatment), and four developed tachycardia which was treated with propranolol. The incidence of pain, and the requirements for treatment of adverse effects during drug administration were significantly higher ( $p<0.025$, Chi square) in the nalbuphine group.

\section{Extubation}

The mean time to extubation after fentanyl administration was $11.3 \pm 1.0 \mathrm{hrs}$ in the saline group, and $9.9 \pm 0.3 \mathrm{hrs}$ in the nalbuphine group, excluding the three patients who received morphine during the 
drug administration. There is no difference (unpaired $t$ test) between these times. While the times to extubation are given for completeness, they were influenced by the study protocol and should not be interpreted as an independent measure of respiratory depression.

\section{Postoperative course}

There were no adverse effects during measurement of the $\mathrm{CO}_{2}$ response curves. No patient required reintubation and no additional nalbuphine or other narcotic antagonist was required. Excluding the three patients who required morphine immediately after nalbuphine administration, the morphine requirements of both groups were not different in the following 12 hours.

There was no difference in the blood loss or blood/fluid requirements between the two groups in the 12 hours following drug treatment. There were no differences in the incidence and severity of EKG and chest $x$-ray changes between the two groups either at 24 or 48 hours post-operation. One patient (who was randomized to the nalbuphine group) had EKG evidence of a new intraoperative myocardial infarction on the first, and all other postoperative cardiograms. However, this patient did well clinically. There were no other major cardiopulmonary complications.

\section{Discussion}

The results show a significant lowering of resting $\mathrm{PETCO}_{2}$ with nalbuphine, but at the price of a significant increase in pain. Administration of saline did not significantly reduce resting $\mathrm{PETCO}_{2}$, nor was there an increase in undesirable side effects.

Our inability to perform a ventilatory response to $\mathrm{CO}_{2}$ in half of the patients at the pre-test drug stage made analysis of this aspect of the results difficult. Even when Friedman's rank test was performed on the slope of the $\mathrm{CO}_{2}$ response results utilizing all the patients as described, the within-patient variability in slopes obscured any drug effect which may have been present. We were surprised that there were no differences from the preoperative and postoperative measured slopes in the saline group. After the high dose of fentanyl, and in association with elevation of $\mathrm{PETCO}_{2}$, depression in the slope was expected. ${ }^{16}$

Most studies utilizing the ventilatory response to $\mathrm{CO}_{2}$ have not been on awake, intubated, postopera- tive patients, and none have been conducted postcardiac surgery. This method of assessing respiratory depression is more sensitive than resting $\mathrm{CO}_{2}$ levels. ${ }^{17}$ Degree of arousal affects the slope of the response, ${ }^{17}$ and our patients certainly experienced varying levels of comfort, alertness, and stimulation throughout the postoperative period. We do not know whether such factors could outweigh the depressant effect of fentanyl on the ventilatory response to $\mathrm{CO}_{2}$. As a result, and due to the small number of patients we were able to assess before nalbuphine, the results do not permit us to conclude that there was either a significantly different slope postoperatively compared to control, or that either saline or nalbuphine had a significant effect on the slope.

The resting $\mathrm{PETCO}_{2}$ results do indicate antagonism of respiratory depression with nalbuphine. The degree of respiratory depression present before nalbuphine was given suggests that many of the patients in this group may not have met extubation criteria when they did, had it not been for the drug. The greater degree of respiratory depression present in this group compared to the saline group before drug administration, however, makes comparison of the groups (i.e., drug vs "placebo") difficult.

The pharmacodynamics of fentanyl related to the respiratory system appear to be highly variable. In our 20 patients respiratory depression ranged from minimal to severe, eight to ten hours after our induction dose. This is in keeping with other studies of both the respiratory and analgesic effects of smaller doses of fentanyl. ${ }^{18-20}$ Thus, despite the prediction that unacceptable respiratory depression should persist until 12 hours after a dose of $40 \mu \mathrm{g} \cdot \mathrm{kg}^{-1}$ of fentanyl, we found that six of 20 patients had a resting $\mathrm{PETCO}_{2}$ of less than or equal to $6.7 \mathrm{kPa}(50 \mathrm{mmHg})$ only eight hours after this dose. The greater elevation in $\mathrm{PETCO}_{2}$ in the nalbuphine group at the pre-treatment stage despite randomization may have been a result of this large variation, coupled with the small sample size. Certainly there was no difference between groups in the preoperative slope, resting $\mathrm{PETCO}_{2}$, or any other factor (Table II), nor was any difference apparent after the drugs had been given.

The very disturbing aspect of our results appears in Table IV. At approximately 4 hours following surgery, only three of the 20 patients experienced slight discomfort. Following the injection of saline 
or nalbuphine a clear difference with respect to pain emerges between the two groups. In the saline group, the one patient with slight discomfort became pain-free following the injection, while two other individuals developed either slight discomfort or tolerable pain. In contrast, the slight discomfort experienced by two individuals before administration of nalbuphine progressed to pain sufficiently severe that the injection had to be discontinued. Of the remaining eight patients initially pain free, only two remained so after nalbulphine administration. All the others developed pain that necessitated cessation of the injection, and three patients required intravenous morphine to control their pain.

This is in contrast to a recent report where adequate analgesia was maintained following the administration of nalbuphine to patients after fentanyl anaesthesia. ${ }^{10}$ In that study, $20 \mathrm{mg}$ of nalbuphine was given immediately on arrival in the recovery room. In our study, much smaller doses of nalbuphine were given some eight hours after a much larger dose ( $1 \frac{1}{2}$ to 2 times) of fentanyl. There were in addition major differences between our patients and those of Latasch et al. Our patients had major and lengthy surgery while those in the Latasch study had "elective general surgery" lasting a mean of 80 minutes.

The mechanism of pain relief after agonistantagonist opiates given in the presence of pure agonist agents is unclear. We suspect the different results of the two studies may arise as a result of the very different doses of both fentanyl and nalbuphine administered. In our study, a very small dose of nalbuphine $\left(5.5 \pm 1.1 \mathrm{mg}\right.$ ) after $40 \mu \mathrm{g} \cdot \mathrm{kg}^{-1}$ of fentanyl seemed to act mainly as an antagonist, while in the study by Latasch $20 \mathrm{mg}$ of nalbuphine after a mean dose of $22.5 \mu \mathrm{g} \cdot \mathrm{kg}^{-1}$ of fentanyl appeared to act as a true agonist-antagonist. It may be that a higher bolus dose of nalbuphine would have resulted in less reversal of analgesia in our patients.

Concomitant with the development of pain, a number of patients receiving nalbuphine developed tachycardia and/or hypertension. It is not surprising that a sympathetic response should accompany pain. What is surprising to us is the unpredictability of the response. Some patients after very little nalbuphine developed all the expected signs of narcotic antagonism, while others developed none even after the full $10 \mathrm{mg}$ had been given. Once the drug had been given, many of the patients who had experienced increasing discomfort became more comfortable, and they did not require more analgesia in the following 12 hours than those who did not receive the drug. Once again, large differences in individual patient pharmacodynamic effects appear to exist.

As a result of these severe adverse responses, we believe that nalbuphine, as given in this study, may be hazardous after a large dose of fentanyl for major surgery. Especially in this group of patients where myocardial oxygen balance is critical, ${ }^{21}$ pain and other sympathetic responses are undesirable. Severe consequences have resulted from antagonism of narcotic drugs after major surgery with naloxone. ${ }^{22,23}$ In addition, any technique which results in increased pain to patients is unacceptable. Thus, the results suggest that reversal of respiratory depression should not be attempted in these patients with small doses of nalbuphine.

Despite these disappointing and worrisome results with low-dose nalbuphine, our results do suggest that our patients, given $40 \mathrm{mg} \cdot \mathrm{kg}^{-1}$ of fentanyl at the start of anaesthesia, did not experience morbidity as a result of their early extubation. Patients who received saline were able to be extubated at a similar time following fentanyl administration as those who received nalbuphine. Thus with close monitoring of respiratory status, such patients who are healthy apart from their coronary artery disease, and who have preserved ventricular function, can be considered for extubation within a few hours of aortocoronary bypass surgery. This conclusion should not be generalized to patients receiving much higher doses of fentanyl, as is common in some centres, however. Further study is required to (a) clarify the relationship of high dose fentanyl pharmacokinetics to the respiratory effects in patients, and (b) clarify the relationship between resting $\mathrm{PETCO}_{2}$ and the slope of the ventilatory response to $\mathrm{CO}_{2}$ after cardiac surgery and this dose of fentanyl. Further study is also needed to determine if a higher bolus dose of nalbuphine would selectively reverse respiratory depression after high dose fentanyl anaesthesia, without precipitating the complications seen in this study. 


\section{References}

1 Stanley $T H$, Webster $L R$. Anesthetic requirements and cardiovascular effects of fentanyl-oxygen and fentanyl-diazepam-oxygen anesthesia in man. Anesth Analg 1978; 57: 411-6.

2 Stanley TH, Philbin DM, Coggins CH. Fentanyloxygen anaesthesia for coronary artery surgery: cardiovascular and anti-diuretic hormone responses. Can Anaesth Soc J, 1979; 26: 168-77.

3 Quasha AL, Locker N, Feeley TW, Ullyot DJ, Roizen MF. Postoperative respiratory care: a controlled trial of early and late extubation following coronary-artery bypass grafting. Anesthesiology 1980; 52: 135-41.

4 Klineberg PL, Geer RT, Hirsch RA, Aukberg SJ. Early extubation after coronary artery bypass graft surgery. Crit Care Med, 1977; 15: 272-4.

5 Prakash $O$, Jonson B, MeijS et al. Criteria for early extubation after intracardiac surgery in adults. Anesth Analg 1977; 56: 703-8.

6 Shackford SR, Virgilio RW, Peters RM. Early extubation versus prophylactic ventilation in the high risk patient: a comparison of postoperative management in the prevention of respiratory complications. Anesth Analg 1981; 76-80.

7 Jaffe JH, Martin, WR. Opioid analgesics and antagonists. In Gilman AG, Goodman LS, Gilman A. (eds.): The Pharmacological Basis of Therapeutics. 6th Ed. New York, MacMillan, 1980, pp. 494-534.

8 Duckworth EN, Lake VL, DiFazio CA, Magruder $M D$. Cardiovascular effects of nalbuphine in patients with or without valvular heart disease. Anesthesiology 1982; 57: 498-503.

9 Magruder MR, Delaney RD, DiFazio CA. Reversal of narcotic induced respiratory depression with nalbuphine HCl. Anesthesiology Reviews, 1982; 9: 34-7.

10 Latasch L, Probst S, Dudziak R. Reversal by nalbuphine of respiratory depression caused by fentanyl. Anesth Analg 1984; 63: 814-6.

11 Sprigge JS, Wynands JS, Whalley DG et al. Fentanyl infusion anesthesia for aortocoronary bypass surgery: plasma level and hemodynamic response. Anesth Analg 1982; 61: 972-8.

$12 \mathrm{McClain} D A, \mathrm{Hug} C J$. Intravenous fentanyl kinetics. Clin Pharmacol Ther, 1980; 28: 106-14.

13 Lake CL, DiFazio CA, Duckworth EN, Moscicki JC, Engle JS, Durbin CG. High-performance liquid chromatographic analysis of plasma levels of nal- buphine in cardiac surgical patients. J Chromatogr 1982; 233: 410-16.

14 Read DJC. A clinical method for assessing ventilatory response to $\mathrm{CO}_{2}$. Aust Ann Med 1967; 16: 20-32.

15 Scott J, Huskisson EC. Graphic representation of pain. Pain 1976; 2: 175-84.

16 Harper MH, Hickey RF, Cromwell TH. Linwood S. The magnitude and duration of respiratory depression produced by fentanyl and fentanyl plus droperidol in man. J Pharmacol Exp Ther 1976; 199 464-8.

17 Nunn JF. Applied Respiratory Physiology, 2nd Edition. London, Butterworths; 1977, pp. 30-1.

18 Lehman $K A$, Freier J, Daub D. Fentanylpharmakokinetik und postoperative atemdepression. Anaesthetist 1982; 31: 111-8.

19 Cartwright $P$, Prys-Roberts $C$, Gill $K$, Dye A, Stafford $M, G r a y C$. Ventilatory depression related to plasma fentanyl concentrations during and after anaesthesia in humans. Anesth Analg 1983; 62: 966-74.

20 McQuay HJ, Bullingham RES, Moore RA. Acute opiate tolerance in man. Life Science 1981; 28: 2513-7.

21 Loeb HS, Sandye A, Croke RP, Taland JV, Kodnyck $M L$, Gunner RM. Effects of pharmacologically induced hypertension on myocardial ischaemia and coronary hemodynamics in patients with fixed coronary obstruction. Circulation 1978; 57; 41-6.

22 Flacke JW, Flacke WE, Williams GD. Acute pulmonary edema following naloxone reversal of high-dose morphine anesthesia. Anesthesiology 1977; 47: 376-8.

23 Estilio $A E$, Cottrell JE. Naloxone, hypertension, ruptured cerebral aneurysm. Anesthesiology 1981; 54: 352 . 
Résumé

La possibilité d'antagoniser sélectivement la dépression respiratoire morphinique consécutive à l'anesthésie par le fentanyl a élé etudié chez 20 patients ayant subi une chirurgie de revascularisation coronaire. Quarante $\mu \mathrm{g} \cdot \mathrm{kg}^{-1}$ de fentanyl ont été administrés d tous les patients, ventilés en oxygène pur avec de l'isoflurane si necessaire. Des doses croissantes de nalbuphine ou de serum salé isotonique ont été administrées au hasard et en double aveugle, quatre heures environ après le circulation extracorporelle. La dépression respiratoire a été évaluée par la mesure des gaz du sang artériel et de la ${ }_{p} \mathrm{CO}_{2}$ téléexpiratoire $\left(\mathrm{PETCO}_{2}\right)$. La réponse ventilatoire au $\mathrm{CO}_{2}$ a été étudiée avant et à intervalles réguliers, après l' intervention. Malgré la répartition au hasard des patients on retrouve dans le groupe soumis à la nalbuphine ceux présentant une depression respiratoire plus marquée. La nalbuphine a provaqué une diminution de la dépression respiratoire morphinique post operatoire comme l'indiquent la châte de la $\mathrm{PETCO}_{2}$. L'évidente diminution de la dépression respiratoire fut cependant associée d une augmentation notable de la douleur. Nous concluons que l' utilisation de faibles doses de nalbuphine pour antagoniser les dépressions respiratoires profondes n'est pas une méthode d recommander chez ce type de patients. La plupart des patients n'ayant pas reçu de nalbuphine furent capables de respirer normalement plus tôt que prévu. Un monitorage attentif de la ventilation pourrait donc permettre une extubation précoce sans l'aide d' un antagoniste morphinique après l' administration de la posologie de $40 \mathrm{\mu g} \cdot \mathrm{kg}^{-1}$ de fentanyl. 